\title{
The use of augmented visual feedback on the learning of the recovering phase of pedaling
}

\author{
Guilherme Garcia Holderbaum, Antônio Carlos Stringhini Guimarães, \& \\ Ricardo Demétrio de Souza Petersen \\ Exercise Research Laboratory - Physical Education School, UFRGS \\ Porto Alegre, RS, 90690-200
}

\section{The use of augmented visual feedback on the learning of the recovering phase of pedaling}

\begin{abstract}
The objective of this study was to investigate if the use of augmented visual feedback would improve the learning of the pedaling technique in the recovery phase. Nineteen people from 14 to 16 years old with no experience in cycling divided in experimental $(n=10)$ and control $(n=9)$ groups took part in this study. Initially, two evaluations were performed to determine the maximal oxygen uptake and work load. Right after the second evaluation seven pedaling practice sections were performed and after the last one a post test was conducted. After a week a retention test was performed. The results showed that both groups increased their performance, but the experimental group showed better results in the retention test. It was concluded that the augmented visual feedback could be considered a more appropriate tool for teaching of cycling.
\end{abstract}

Key Words: Cycling, recovery phase, augmented visual feedback, motor learning, biomechanics.

\section{Introdução}

A Pedaling a bicycle seems to be easy to learn since most of the children end up riding a bike. However, learning the right technique is not as trivial as it seems to be. The pedaling technique depends on the good direction of the forces applied to the pedal in the propulsion phase as much as in the recovery phase (Figure 1) (Henke, 1998; Holderbaum et al., 2005; Holderbaum et al., 2006a; Holderbaum et al., 2006b; Holderbaum et al., 2006c).

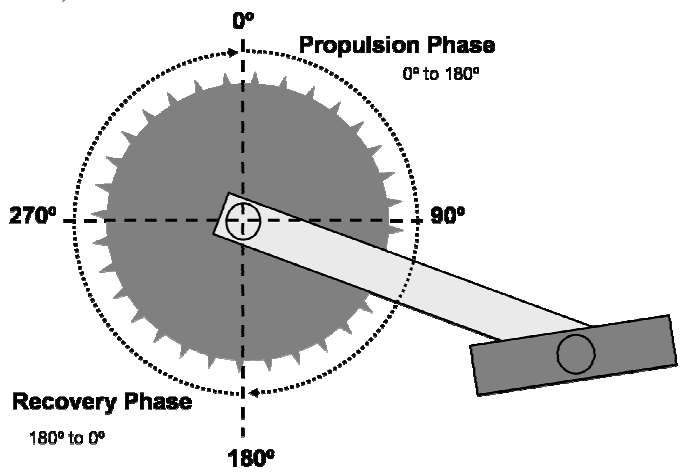

FIGURE 1: Pedaling cycle (from $0^{\circ}$ to $360^{\circ}$ ) divided in two phases. Propulsion phase (from $0^{\circ}$ to $180^{\circ}$ ) and recovery phase (from $180^{\circ}$ to $0^{\circ}$ ) along the pedaling cycle.

The forces applied to the pedal are measured in terms of their components. These components are termed shear force component $(\mathrm{Fx})$, that has its direction in the anterior-posterior axis, and acts to the surface of the pedal and normal force component (Fy) that has its direction in the longitudinal axis, acting perpendicularly to the surface of the pedal (Figure 2) (Lafortune \& Cavanagh, 1983; Ericson \& Nissel, 1988; Neptune \& Herzog, 1999; Neptune \& Herzog, 2000; Gruben et al., 2003a; Gruben et al., 2003b; Sanderson \& Black, 2003).

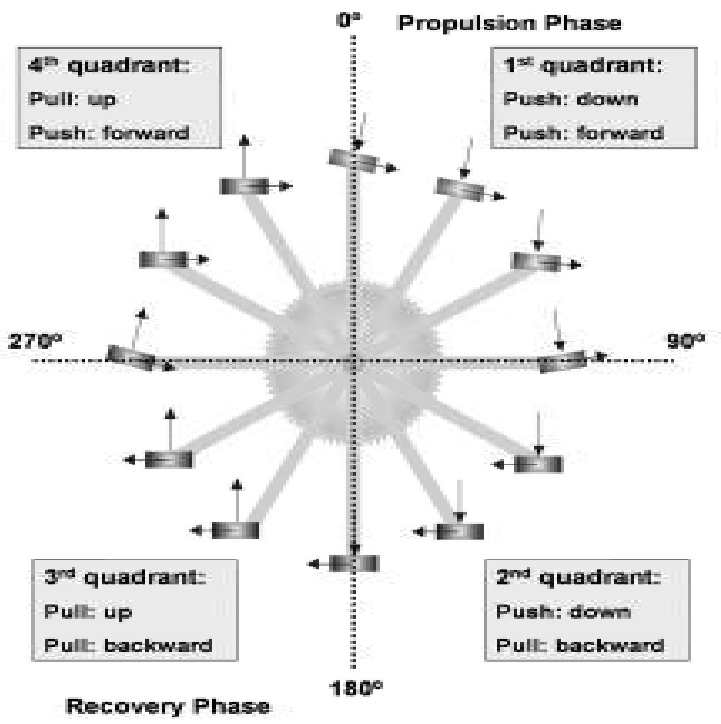

FIGURE 2: Ideal directions of the forces applied to the pedal in the propulsion phase and in the recovery phase along the pedaling cycle. 
The forces applied to the pedal are measured in terms of their components. These components are termed shear force component $(\mathrm{Fx})$, that has its direction in the anterior-posterior axis, and acts to the surface of the pedal and normal force component (Fy) that has its direction in the longitudinal axis, acting perpendicularly to the surface of the pedal (Figure 3) (Lafortune \& Cavanagh, 1983; Ericson \& Nissel, 1988; Neptune \& Herzog, 1999; Neptune \& Herzog, 2000; Gruben et al., 2003a; Gruben et al., 2003b; Sanderson \& Black, 2003).

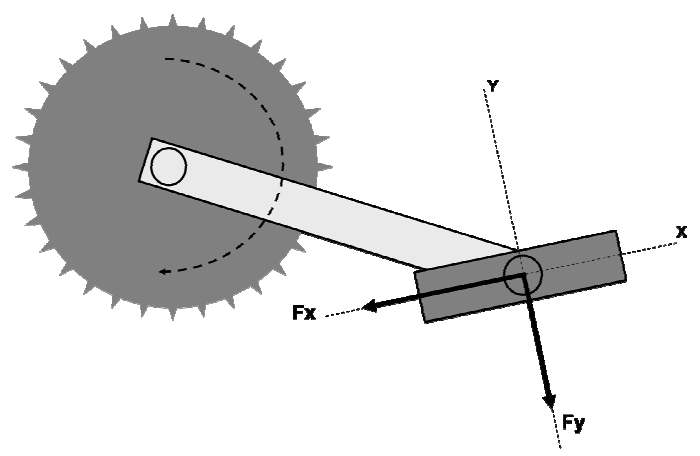

FIGURE 3: Shear force component (Fx) and normal force component (Fy) applied to the surface pedal.

The suitable direction of these two components of force along the pedaling cycle represents the efficient pedaling technique (Lafortune \& Cavanagh, 1983; Burke, 1996; Gregor, 2000). To improve the pedaling technique, studies related to the cycling teaching have been using the augmented visual feedback (AVF) that consists of given information to the learner in order to improve their pedaling technique (Sanderson \& Cavanagh, 1990; Broker et al., 1993; Henke, 1998). Besides AVF on line, studies still use pedaling cadence between 60 and $80 \mathrm{rpm}$ and fixed work load between 112 and 200w.

Unlike the published studies about teaching of cycling, that used resultant force (RF), shear force (Fx) and index of effectiveness (IE) as reference of the visual augmented feedback (Sanderson \& Cavanagh, 1990; Broker et al., 1993; Henke, 1998), this study used the effective force (EF) (Figure 4). This, in turn, is the force that is used in the propulsion of the bike and depends on the magnitude and direction of forces applied to the pedal, so is presented as a key component for the movement of the pedaling technique.

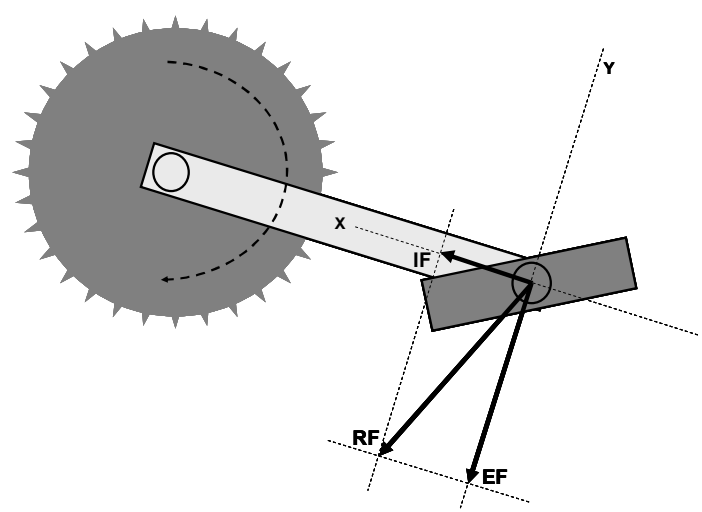

FIGURE 4: Effective force applied perpendicularly to the crank. This force is used in the propulsion of the bike and depends on the magnitude and direction of forces applied to the surface pedal.

The present study, besides using summary feedback (unlike the on line feedback that provides information in real time, the summary feedback consists of information about the task that has just been completed), cadence of $60 \mathrm{rpm}$ (due to the relation between speed and accuracy) still has a physiological normalization of the work load in order to keep all individuals in the same intensity of exercise. Therefore, the purpose of this study was to investigate if the use of augmented visual feedback would improve the learning of the pedaling technique in the recovery phase.

\section{Participants}

\section{Methods}

Nineteen male from fourteen to sixteen years of age took part in this study. They were divided into experimental $(n=10)$ and control $(n=9)$ groups. The participants signed written informed consent. This study was approved by the Research Commission of the Physical Education School of the Federal University of Rio Grande do Sul - UFRGS.

\section{Procedures}

The experiment was divided in three parts: (1) pre-experiment period, to determine the maximal oxygen uptake $\left(\mathrm{VO}_{2 \text { máx }}\right)$ and the work load corresponding to $60 \%$ of the $\mathrm{VO}_{2 \text { máx }}$ in order to establish criteria of physiological normalization of the work load for all the individuals; (2) seven days of practicing the pedaling technique for 30 minutes, cadence of $60 \mathrm{rpm}$ and load of $60 \%$ of the $\mathrm{VO}_{2 \text { máx }}$; and (3) period of post-experiment that consisted of two tests, one right after the last practice session (post-test) and another after a week (retention test). 
During the practice sessions, both groups received verbal augmented feedback (AF), however only the experimental group received augmented visual feedback (AVF) that consisted of a graphic presentation of the curve of effective force (EF) applied to the pedal overlapped to the curve of effective force reference produced by an elite athlete from the Gaúcha Federation of Cycling. These curves were presented to individuals on a computer screen. Thus, it was possible to show to the individual how far or near his technique was from the technique of an elite cyclist.

The period of practice sessions took seven days and it was divided into two phases: phase $1\left(1^{\text {st }}\right.$ to $5^{\text {th }}$ day) and phase $2\left(^{\text {th }}\right.$ to $7^{\text {th }}$ day $)$. Each practice session lasted 35 minutes. The first five minutes were without feedback, because they were only for warming up and individual familiarization with the bike. In both phases the pedaling rate was $60 \mathrm{rpm}$.

In the 30 minutes left, both the individuals of the experimental and the control groups received $\mathrm{AVF}$ and $\mathrm{AF}$, respectively, in an alternated way, in order of not delaying the learning. Feedback (AVF and $\mathrm{AF}$ ), in any of the practice sessions, was provided with participants not pedaling.

From the $1^{\text {st }}$ to the $5^{\text {th }}$ day of practice, the experimental and control groups received AVF and $\mathrm{AF}$ during one minute, respectively, for each series of one-minute pedaling, so they pedaled one minute and received the corresponding feedback of that minute. With this strategy both groups received a total of 75 minutes of feedback for 75 minutes of pedaling in the first phase of the practice sessions ( 5 sessions of 15 -minutes pedaling and 15 minutes of feedback).

From the $6^{\text {th }}$ to $7^{\text {th }}$ day of the practice sessions, the experimental and control groups received AVF and AF during one minute, respectively, for each 2minutes series of the practice sessions, so they pedaled for 2 minutes and received the feedback corresponding to those 2 minutes, a total of 20 minutes of feedback to 40 minutes of pedaling in the second phase of the practice sessions (2 sessions of 20 minutes of pedaling and 10 minutes of feedback).

The feedback was presented to the individuals at the end of each acquisition of the dynamometry and eletrogoniometry signs, that is, in the interval between the pedaling series when the individuals were not pedaling, but just receiving the feedback about their pedaling technique. The verbal information given to both groups were related to the direction of the applied forces on the pedal (Figure 2).
By the end of the practice sessions the experimental and control groups received, respectively, 75 minutes of $\mathrm{AVF}$ and $\mathrm{AF}$ from the $1^{\text {st }}$ to $5^{\text {th }}$ day (phase 1 ) and 20 minutes from $6^{\text {th }}$ to $7^{\text {th }}$ day (phase 2), totalizing 95 minutes feedback for both groups during seven days of practice sessions. Therefore, feedback reduction from phase 1 to phase 2 was about $73 \%$ and was used to avoid dependence on feedback (Sanderson \& Cavanagh, 1990).

In the post-experiment period, the groups did not receive feedback. It was also divided into two days of evaluation, with the first one immediately after the last learning session, the post-test, and the second one occurring one week after the post-test, the retention test.

The register of the dynamometry and eletrogoniometry signs were captured in the three stages of the study and for its analysis an average of ten cycles of pedaling was used. From the decomposition of the normal and shear forces in relation to the crank it was possible to calculate the effective force (EF) (equation 1) that consists of the sum of the components of the normal (Fy) and shear (Fx) forces perpendicular to the crank, using the angle of the pedal related to the crank (Broker \& Gregor, 1990).

$$
E F=F y^{\perp}+F x^{\perp} \text { (1) }
$$

After knowing the values of the EF, it was possible to obtain the negative and positive values along the cycle. For this, all the negative and positive intervals of the EF curve were cut and integrated. Afterwards all the integrated negative and positive values were summed and then the total values of positive and negative EF were obtained. The resulting force (RF) applied to the pedal was calculated from the decomposition of the normal Fy and shear forces (equation 2). The instrument used in this study did not allow measurement of the component of side-medium force, so, this resulting force applied to the pedal represents the total force in the sagital plan.

$$
R F=\sqrt{F y^{2}+F x^{2}}
$$

Later the impulses of effective force (IEF) and resulting force (IRF) (equations 3 and 4 respectively) were calculated (Lafortune \& Cavanagh, 1983).

$$
I E F=\int_{0}^{x} d t E F
$$




$$
I R F=\int_{0}^{x} d t R F
$$

The padaling technique of the individual along the cycle was analyzed through the index of effectiveness (IE). This consists of the ratio between the IEF and the IRF (equation 5). The IE indicates how much the RF was directioned as EF, that is, used for the bicycle propulsion (Lafortune \& Cavanagh, 1983; Sanderson \& Cavanagh, 1990).

$$
I E=\int_{0}^{x} d t E F / \int_{0}^{x} d t R F
$$

After this procedure, the IE in the recovery phase $\left(180^{\circ}\right.$ to $\left.360^{\circ}\right)$ was calculated.

\section{Statistical Analysis}

A descriptive analysis of data was performed calculating the mean and the standard deviation. Once verified normality, homogeinity, and esfericity (Shapiro - Wilk, Levene and Mauchly, respectively), an ANOVA with repeated measures and post-hoc tests of Bonferroni were employed to verify possible differences among the moments. For the comparison inter-groups, it was applied a $\mathrm{T}$ Test of Student for the independent data. A software SPSS (version 12.0) was used and it was adopted $\mathrm{p} \leq 0,05$ as significant level.

\section{Results}

Table 1 presents the results of the index of effectiveness (this indicates how much the total force applied to the pedal was used for the bicycle propulsion) in the recovery phase of the two sample groups.

TABLE 1: Average of index of effectiveness (\%) in the recovery phase of the experimental (Exp) and control (Con) group on the three evaluated moments.

\begin{tabular}{cccc}
\hline & Pre & Pos & Retention \\
\hline Exp & $-52( \pm 5)^{*}$ & $-15( \pm 31)^{*}+$ & $13( \pm 27)^{*}+$ \\
Com & $-53( \pm 4)^{*}$ & $-26( \pm 20)^{*}+$ & $-32( \pm 27)^{*}$ \\
\hline
\end{tabular}

$*$ indicates significant difference between pre and post and pre and retention moments $(\mathrm{p} \leq 0.05)$.

+ indicates significant difference post and retention moments $(\mathrm{p} \leq 0.05)$.
In the intra-group comparison of the IE, the experimental group presented significant increase in the average of IE in the recovery phase from the pre- to the post-moment, from the pre- to the retention moment and from the post- to the retention moment. The control group presented significant increase between the pre- and the postand pre- and retention moments. In the inter-groups comparison there were no differences noticed in the pre- and post- moments, only in the retention moment. Figure 5 shows the average the values of the negative $\mathrm{EF}$ along the pedaling cycle for both groups. The negative EF is considered as retarding forces that show up to difficult the bicycle propulsion in the recovery phase since there is torque to the opposite sense of the movement (Sanderson \& Black, 2003).

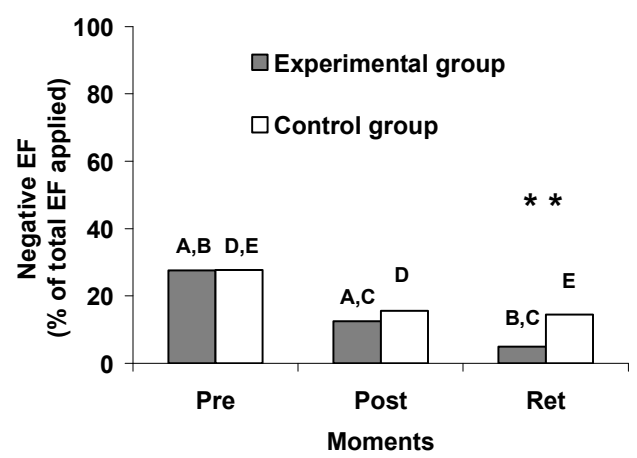

FIGURE 5: Comparison of the average negative EF of the experimental and control groups in the three evaluated moments. Note: Equal letters indicates intragroup significant difference. $* *$ indicates inter-group significant difference.

In the intra-group comparison of the $\mathrm{EF}$, the experimental group presented significant reduction in the average application of negative EF in the preand post moments, pre- and retention moments as well as post- and retention moments. The control group presented significant reduction only between the pre- and post moments, and pre- and retention moments. In the inter-groups comparison it was noticed the significant difference in the average of application of negative EF only in the retention moment.

\section{Discussion}

Motor learning is characterized by stable levels in the performing of a given task (Singer, 1975; Magill, 2000; Schmidt \& Wrisberg, 2001; Wishart et al., 2002; WULF et al., 2002). From the results obtained in this study, it is possible to suggest that both groups learned the pedaling technique of the recovery phase. The feedback providing to the 
individuals seems to be responsible for the increasing in the average of the IE in the recovery phase and by the reduction of the negative EF along the cycle in both groups. Since the frequency of feedback was reduced from phase one to phase two, the individuals start to use the intrinsic feedback which allowed them the detection and correction of errors, resulting in less dependence of the feedback (Tani et. al, 2004).

The experimental group which received AVF presented a pedaling technique in the recovery phase more consistent than the control group. It is justified by the fact that this group increased significantly its average of IE in the recovery phase and decreased significantly its average of negative EF along the cycle in the retention test. This fact may be due to a better direction of the force components applied to the pedal specifically in the recovery phase because according to Lafortune and Cavanagh (1983), Sanderson and Cavanagh (1990) and Broker et al. (1993) a better direction of the force components applied to the pedal results in a more efficient pedaling technique.

The average IE in the experimental group, in the recovery phase, agrees with the results of Henke (1998) with regard to a better use of forces in pedaling. HENKE (1998) evaluated the IE in the recovery phase, dividing its analysis by quadrant, which also represents an interesting way to examine the presence of retarding forces. This author used AVF, and found significant results in $3^{\text {rd }}$ and $4^{\text {th }}$ quadrants, with increases in performance in the order of $15 \%$ and $62 \%$ respectively.

SANDERSON and CAVANAGH (1990) found significant results when analyzed the reduction of retarding forces in the recovery phase, it reduced the presence of RF at this phase by almost half. Although in this study RF in the recovery phase was not evaluated, it is possible to say that the results the present study agree with the results of SANDERSON and CAVANAGH (1990), because there was a reduction in negative $\mathrm{EF}$ of approximately $27 \%$ at the pre moment for approximately $5 \%$ at the retention moment. It is interesting to note that the value of negative $\mathrm{EF}$ of $5 \%$ reached in of the experimental group is about five times lower than the value obtained by the same group at the pre moment, which represents a large reduction in negative EF over pedaling cycle.

The results of the control group also agree with the study of SANDERSON \& CAVANAGH (1990), because that group showed a reduction of approximately $27 \%$ at the pre moment to $14 \%$ at the retention moment, which represents almost half of the value obtained in the pre moment. However, these results from the control group did not corroborate with the results found by Henke (1998), in which the control group failed to decrease the amount of negative $\mathrm{EF}$ in the fourth quadrant. Although the negative EF in this study was not examined for each quadrant, it is possible to say that as there was a decrease throughout the pedaling cycle it is very likely that individuals from the control group have managed to pull the pedal in the recovery phase, thus decreasing the amount of negative EF applied to the pedal in the $3^{\text {rd }}$ and $4^{\text {th }}$ quadrants, which contradicts the findings of Henke (1998).

The improvement in the force application to the pedal by the experimental group may be related to the quality of information contained in the AVF. This allows the attribution of a relevant meaning to the visual information transmitted, allowing its storing in the long-term memory (Klatzky, 1980; Holderbaum et al., 2005; Holderbaum et al., 2006a; Holderbaum et al., 2006b; Holderbaum et al., 2006c) accomplishment of the task (Magill, 2000; Godinho, 2000).

Although the control group significantly increased the average of IE in the recovery phase and significantly decreased the average of application of negative IE after the practice sessions, it did not manage to keep the same performance in the retention test. This fact may be related to the absence of visual information that made it difficult the attribution of a relevant meaning to the permanent storing of information (Klatzky, 1980; Holderbaum et al., 2005; Holderbaum et al., 2006a; Holderbaum et al., 2006b; Holderbaum et al., 2006c).

\section{Conclusion}

The results of this study showed that the AVF and the AF are appropriate tools to improve the performance of the pedaling technique in the recovery phase. However, the AVF besides improving the direction of the force components applied to the pedal, it is more efficient in the learning process.

\section{References}

Álvarez, G. \& Vinyolas, J. A. (1996). New Bicycle Pedal Design for On-Road Measurements of Cycling Forces. Journal of Applied Biomechanics, 12, 131-141.

Burke E. R. (1996). High-tech Cycling. Champaign-Urbana: Human Kinetics.

Broker, J. P. \& Gregor, R. J. (1990). A dual piezoelectric element force pedal for kinetics 
analysis of cycling. International Journal of Sports Biomechanics. 6 (4), 394-403.

Broker, J. P.; Gregor, R. J. \& Schmidt, R.A. (1993). Extrinsic feedback and the learning of kinetic patterns in cycling. Journal of Applied Biomechanics. 9, 111-123.

Caldwell, G. E.; Li, L.; McCole, S. D. \& Hagberg, J. (1996). Pedal and Crank Kinetics in Uphill Cycling. Journal of Applied Biomechanics. 14(3), 245-259.

Coyle, E. F.; Feltner, M. E.; Kautz, S. A.; Hamilton, M. T.; Montain, S. J.; Baylor, L. M.; Abraham, L. D. \& Petrer, G. W. (1991). Phisiological and Biomechanical factors associated with elite endurance cycling performance. Medicine and Science In Sports Exercise, 23, 93-107.

Ericson M. O \& Nissel R. (1988). Efficiency of pedal forces during ergometer cycling. International Journal of Sports Medicine, 9, 118-122.

Faria, I. E. (1992). Energy expenditure, aerodynamics and medical problems in cycling. Sports Medicine, 14(1), 43-63.

Godinho, M. (2002). Controlo Motor $e$ Aprendizagem Fundamentos e Aplicações. Lisboa: Faculdade de Motricidade Humana Edições, $2^{\circ}$ ed.

Gregor, R. J. (2000). Biomechanics of cycling. In W.E. Garrret \& D.T. Kirkendall (Eds.), Exercise and Sport Science, p. 515-537. Philadelphia: Lippincott Williams \& Wilkins.

Gruben, K. G.; Rogers, L. M. \& Schmidt, M. W. (2003a). Direction of foot force for pushes against a fixed pedal: role of effort level. Motor Control. 7, 229-241,

Gruben, K. G.; Ortiz, C. L. \& Schmidt, M. W. (2003b). The control of foot force during pushing efforts against a moving pedal. Experimental Brain Research, 148, 148-50-61.

Henke, T. (1998). Real-time feedback of pedal forces for the optimization of pedaling technique in competitive cycling. ISBS'98 Proceedings, p. 174-177.

Holderbaum, G. G.; Bini, R. R.; Nabinger, E. \& Guimarães, A. C. S. (2005). Metodologia para ensino da técnica da pedalada no ciclismo através de um sistema de feedback visual aumentado. Anais do IX Congresso Brasileiro de Biomecânica. João Pessoa, $\mathrm{n}^{\circ} 352$.

Holderbaum, G. G.; Bini, R. R.; Guimarães, A. C. S.; Petersen, R. D. S. (2006a). O uso do feedback visual aumentado no aumento da aplicação de força efetiva no ciclismo. Anais do III Congresso Brasileiro de Comportamento Motor. Rio Claro.
Holderbaum, G. G.; Bini, R. R.; Guimarães, A. C. S.; Petersen, R. D. S. (2006b). O uso do feedback visual aumentado na melhoria da técnica de pedalada no ciclismo. Anais do III Congresso Brasileiro de Comportamento Motor. Rio Claro.

Holderbaum, G. G.; Bini, R. R.; Guimarães, A. C. S.; Petersen, R. D. S. (2006c). O uso do feedback visual aumentado na otimização da economia de movimento no ciclismo. Anais do III Congresso Brasileiro de Comportamento Motor. Rio Claro.

Klatzky, R. L. (1980). Human Memory Structures and Processes. San Francisco: Freeman and Company.

Lafortune, M. A \& Cavanagh, P. R. (1993). Effectiveness and efficiency during bicycle riding. In Matsui, H \& K. Kobayashi (Eds), Biomechanics VIII-B, p.928-936. Champaign, IL: Human Kinetics.

Magill, R. A. (2000). Aprendizagem motora: conceitos e aplicações. São Paulo: Editora Edgard Blucher Ltda.

Neptune, R. R. \& Herzog, W. (1999). The association between negative muscle work and pedaling rate. Journal of Biomechanics, 32, 1021-1026.

Neptune, R. R. \& Herzog, W. (2000). Adaptation of muscle coordination to altered task mechanics during steady-state cycling. Journal of Biomechanics, 33, 165-172.

Sanderson, D. J. \& Black, A. (2003). The effect of prolonged cycling on pedal forces. Journal of Sports Science, 21, 191-199.

Sanderson, D. J. \& Cavanagh, P. R. (1990). Use of augmented feedback for the modification of the pedaling mechanics of cyclists. Canadian Journal of Sport Science, 15(1), 38-42.

Schmidt, R. A. \& Wrisberg, C. A. Aprendizagem e performance motora: Uma abordagem da aprendizagem baseada no problema. Porto Alegre: Artmed Editora, $2^{\circ}$ ed, 2001.

Singer, R. N. (1975). Motor Learning and Human Performance. An application to physical education skills. New York: Macmillan Publishing Inc., $2^{\circ}$ ed..

Tani, G.; Freudenheim, A., N.; Meira Júnior, C., M.; Corrêa, U., C. (2004). Aprendizagem Motora: tendências, perspectivas e aplicações. Revista Paulista de Educação Física, 8, 55-72.

Wishart, L. R.; Lee, T. D.; Cunningham, S. J. \& Murdoch, J. E. (2002). Age-related differences and role of augmented visual feedback in learning a bimanual coordination pattern. Acta Psychologica, 110, 247-263. 
Wulf, G.; Mcconel, N.; Gärtner, M. \& Schwarz, A. (2002). Enhancing the learning of sports skills through external-focus feedback. Journal of Motor Behavior. 34 ( 2), 171-182.

\section{Endereço:}

Guilherme Garcia Holderbaum

Laboratório de Pesquisa no Exercício, Escola de Educação Física, UFRGS

Rua Felizardo, 750, Jardim Botânico

Porto Alegre, RS, CEP 90690-200

e-mail: ghgarcia@ibest.com.br

Submetido: 17 de Novembro de 2007.

Revisado: 21 de Abril de 2008.

Aceito: 23 de Agosto de 2008. 